\title{
PEMANFAATAN TEH HIJAU KUNYIT GARAM (TEKUGA) SEBAGAI INOVASI PRODUK PERAWATAN KECANTIKAN SECARA ALAMI
}

\author{
Reyni Phratini \\ Yurika Wanda Sari \\ Tiya Mustika \\ Fakultas Ekonomi Dan Bisnis Universitas Muhammadiyah Sumatera Utara \\ Jln. Kapten Muchtar Basri No. 3 Medan 20238 \\ Email : reyniphra@gmail.com
}

\begin{abstract}
ABSTRAK
Perawatan kulit wajah sangat dibutuhkan untuk semua orang, dimulai dari usia muda sampai usia lanjut. Khususnya untuk wanita mereka sangat memperhatikan perawatan kulit wajah mereka. Banyak produk perawatan wajah saat ini yang menggunakan bahan kimia karena yang manfaatnya langsung kelihatan, tetapi dapat sangat membahayakan kesehatan mereka terutama bagian kulit mereka. Hal ini sangat perlu diperhatikan oleh para pembeli. Face Scrub Herbal TEKUGA yang dimana bahannya $100 \%$ dari bahan alami yang diracik sendiri menggunakan alat manual agar tetap terjaga khasiatnya. Bahannya terdiri dari teh hijau, kunyit, dan garam. Dari bahan tersebut kita dapat mengetahui sangat banyak khasiat yang terkandung didalamnya ,yaitu: dapat mengencangkan kulit wajah, mengangkat sel kulit mati, membersihkan komedo yang berlebihan, mengurangi minyak pada wajah yang berlebihan, mengatasi masalah pada jerawat,dan membuat kulit terasa lebih halus. Metode pelaksanaannya yaitu mulai dari observasi pasar, persiapan, pembelian bahan baku, pelaksanaan produksi, pengemasan produk, dan pemasaran produk.
\end{abstract}

\section{Kata kunci : Kecantikan, face scrub, dan alami}

\section{ABSTRACT}

Facial skin care is needed for everyone, starting from young to old age. Especially for women they are very concerned about their facial skin care. Many facial care products today use chemicals because the benefits are immediately visible, but can be very dangerous to their health, especially parts of their skin. This is very important for buyers. TEKUGA Herbal Face Scrub, where the ingredients are $100 \%$ from natural ingredients that are formulated by themselves using manual tools to keep their properties awake. The ingredients consist of green tea, turmeric, and salt. From these ingredients we can find out very many properties contained therein, namely: can tighten facial skin, remove dead skin cells, clean excess blackheads, reduce excessive oil on the face, overcome problems in acne, and make skin feel smoother. The method of implementation is starting from market observation, preparation, purchase of raw materials, implementation of production, product packaging, and product marketing.

Keywords: Beauty, face scrub, and natural 


\section{PENDAHULUAN}

Kecantikan merupakan sebuah kebutuhan primer saat ini bagi kaum wanita. Tampil memukau dilingkungan sekitar bagi wanita merupakan sebuah tuntutan untuk menunjang sikap percaya diri dalam setiap aktivitas. Kaum wanita menganggap kecantikkan saat ini menjadi suatu barang mewah untuk diperoleh. Pada dasarnya kecantikan dibagi menjadi dua bagian yaitu, Kecantikan bersumber dari dalam dan kecantikan bersumber langsung pada bentuk fisik. Kecantikan dari segi bentuk dan fisik kini menjadi populer di masyarakat sehingga menciptakan banyak solusi atau alternatif untuk mendapatkannya. Cara-cara modern banyak disediakan oleh salon kecantikan, yaitu mulai dari menggunakan laser, suntik, dan bahan kimia lainnya. Tapi menurut riset kedokteran dinyatakan bahwasannya alternatif perawatan kecantikan menggunakan cara modern akan berakibat atau berefek dalam jangka pendek maupun panjang. Akan tetapi ada alternatif yang sudah banyak digunakan oleh pakar kecantikan yaitu menggunakan bahan-bahan herbal atau bahan-bahan alami yang dicampurkan hingga menjadi sebuah media perawatan wajah. Masyarakat lebih dominan percaya terhadap perawatan wajah secara herbal daripada zat kimia yang diperoleh dari berbagai macam bahan kimia. Maka dari itu kami menciptakan produk kecantikan untuk perawatan wajah yang menggunakan bahan bahan alami yang diracik sendiri dengan menggunakan alat manual agar tetap terjaga khasiat nya, yaitu Face Scrub Herbal TEKUGA. Bahan-bahan yang digunakan $100 \%$ dari bahan alami, yang terdiri dari: teh hijau, kunyit, dan garam. Yang khasiatnya adalah dapat menghilangkan jerawat, mengurangi komedo yang berlebihan, mengencangkan kulit wajah, membantu membersihkan sel kulit mati, mengurangi minyak pada wajah yang berlebihan, dan dapat menghaluskan kulit wajah. Face Scrub Herbal TEKUGA merupakan produk jenis kecantikan yang digunakan untuk mengangkat sel kulit mati pada wajah. Namun, tidak mengeluarkan busa seperti layaknya sabun. Berstektur bubuk jauh lebih kasar dan memiliki aroma yang alami, berwarna kuning. Scrub wajah (Face Scrub) adalah produk eksfoliasi (pengelupasan) kulit yang dirancang 
khusus untuk digunakan pada wajah, yang diracik dengan menggunakan bahan-bahan alami seprti kunyit, teh hijau, dan garam yang diolah menjadi produk perawatan untuk wajah.

\section{METODE}

Metode yang digunakan adalah metode mendeskripsikan atau menggambarkan pelaksanaan kegiatan produksi facescrub TEKUGA dengan tahapan sebagai berikut :

\section{Tahapan Pelaksanaan}

adapun tahapan pelaksanaan sebagai berikut:

1. Merancang kegiatan Face Scrub Herbal TEKUGA

Pada proses ini kami merancang kegiatan kegiatan apa saja yang akan dilakukan untuk memulai usaha ini.

\section{Menyiapkan Logo}

Tahap ini kami mendiskusikan desain logo yang kami buat sendiri agar dapat mengenal identitas dari produk ini.

\section{Riset harga pasar}

Kami mencari harga pasaran yang sesuai dengan uang saku anak sekolahan.

4. Menyiapkan Bahan dan alat
Tahap ini kami menyiapkan bahanbahan dan alat-alat yang dibutuhkan untuk proses produksi. Bahannya yaitu, kunyit, teh hijau, dan garam. Alat-alat yang kami siapkan yaitu, Blender untuk menghaluskan bahanbahan, dan bahan pendukung nya seperti pisau, baskom, tampa, dan alat lainnya.

\section{HASIL DAN PEMBAHASAN}

\section{Deskripsi Produk}

Face scrub herbal yang terbuat dari bahan-bahan alami yaitu kunyit, teh hijau dan garam yang mengandung antiseptik, anti inflamasi, anti bakteri, mineral (seperti kalsium, kalium, silikon, natrium dll) yang berfungsi untuk mengatasi masalah jerawat, mengangkat sel kulit mati, mengurangi kantung mata, membantu peremajaan kulit, mencegah kulit berminyak dan membuat kulit terasa lebih halus.

\section{Analisis Kelayakan Usaha}

a. Strenght (Kekuatan)

- Tanpa merkuri

- Tidak ada efek samping

- Mudah dalam pengaplikasiannya

- Lebih memiliki minat beli yang tinggi

- Harga lebih terjangkau

- Desain produk yang menarik 


\section{b. Weakness (Kelemahan)}

- Kepekatan warna dari kunyit dapat membuat kulit wajah menjadi kuning sementara waktu

- Saat diaplikasikan kewajah tidak boleh lebih dari 10 menit

- Menimbulkan gatal pada kulit khusus pada wajah yang sangat sensitif

\section{c. Opportunities (Kesempatan)}

Tingkat minat beli yang cukup besar merupakan pasar potensial yang dapat dijadikan sebagai target penjualan produk. Semakin banyak minat beli kemungkinan untuk menjual produk lebih banyak, sangat terbuka lebar.

\section{Threats (Ancaman)}

- Banyak facescrub yang lain yang lebih dipercaya

- Semakin ketatnya persaingan diantara distributor facescrub

Mekanisme mendapatkan keuntungan:

1. Menetapkan harga produk dengan baik.

2. Koreksi pengeluaran yang terlalu besar.

3. Koordinasikan semua keperluan.

4. Fokus ke pertumbuhan bisnis.

\section{Teknik Pembuatan Komoditas Usaha}

\section{A. Bahan}

1. Teh Hijau 1 Kotak

2. Garam 1 Bungkus
3. Kunyit yang sudah dihaluskan secukup-nya

4. Air secukup-nya

\section{B. Langkah-langkah pembuatan}

- Sediakan Kunyit, Garam dan Teh hijau.
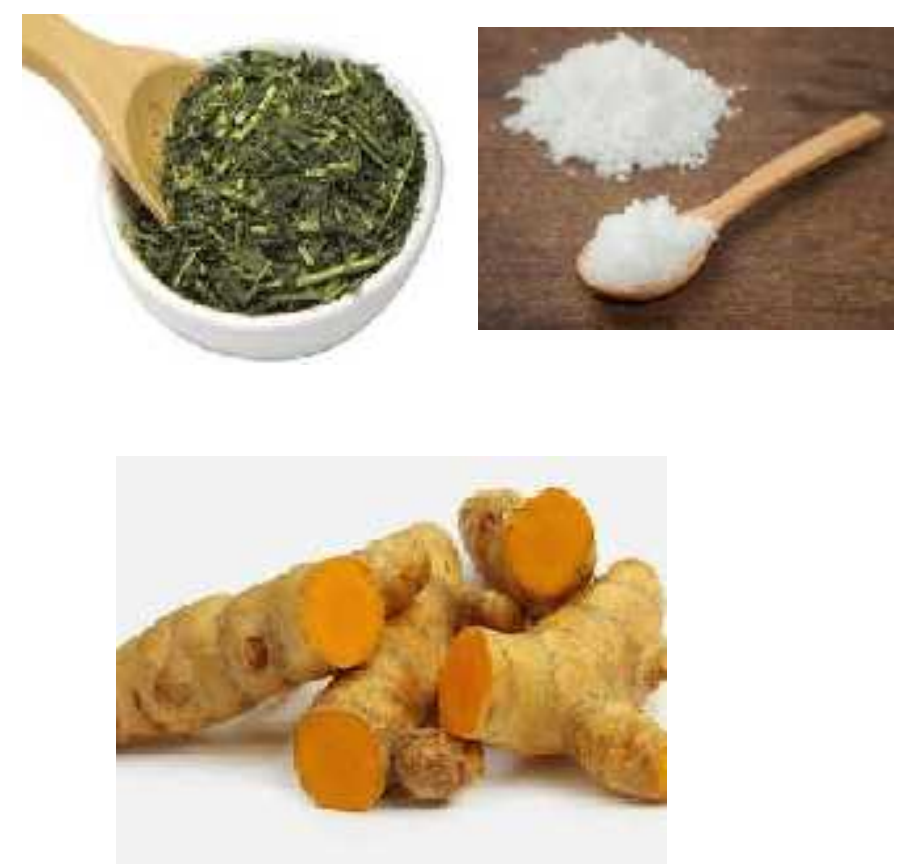

- Lalu masukkan bahan-bahan tersebut kedalam blender

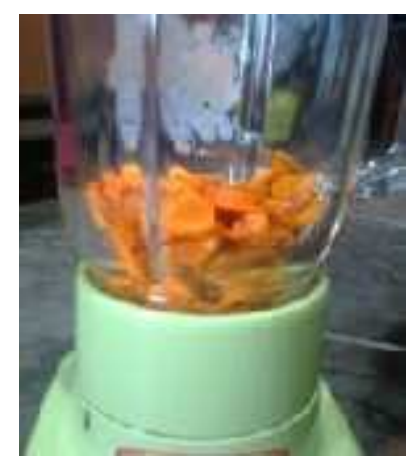

- Kemudian jemur sampai

- $\quad$ kering seperti bubuk 
Liabilities Jurnal Pendidikan Akuntansi e-ISSN 2620-5866

Volume 2. No.2 Agustus 2019 (127-133)

Doi. 10.30596/liabilities.v2i2.3259

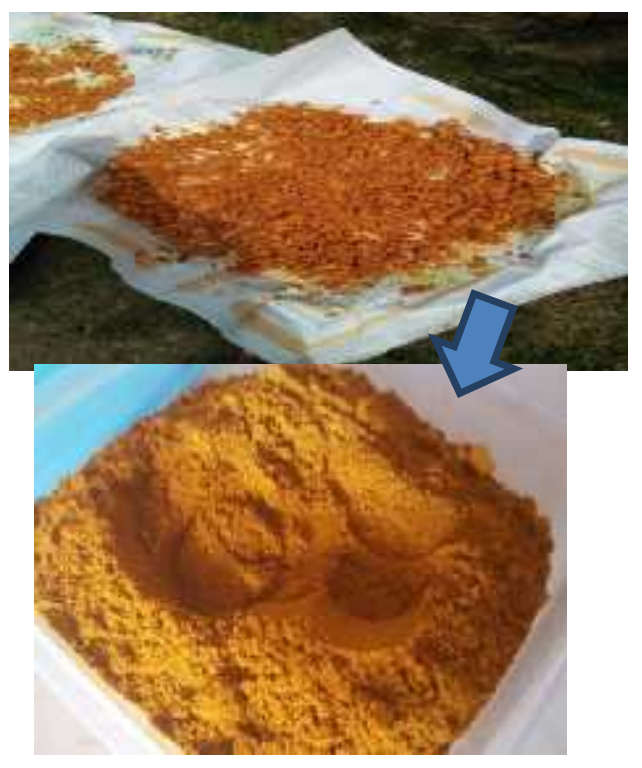

\section{Teknik Pengemasan Komoditas Usaha}

1. Masukkan face scrub yang sudah di keringkan kedalam wadah produk

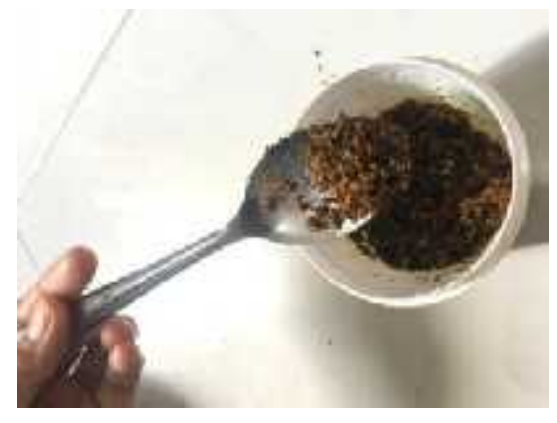

2. Inilah hasil akhir dari pengemasan

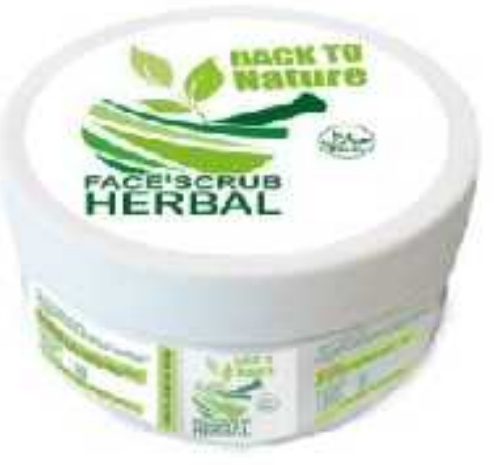

\section{Strategi Pemasaran}

\section{A. Menggunakan Media Sosial sebagai Media Periklanan}

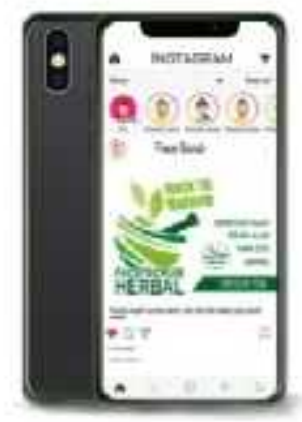

ISLAN INGTAGRAM

\section{B. Brosur}

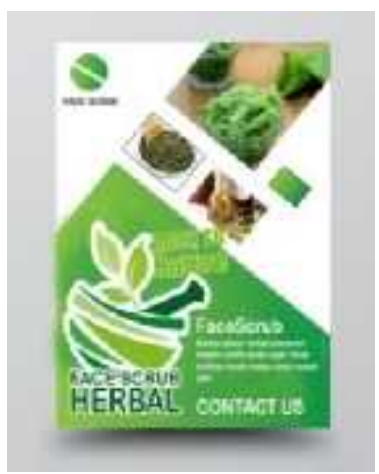

\section{Tahapan Pelaksanaan}

Dalam pengajuan ini, terlampir beberapa poin tahapan pelaksanaan awal produksi sampai akhir produksi yang telah dirangkum secara rinci, diantara-nya :

\section{Ide Produk}

a. Merundingkan jenis produk yang akan di publikasikan. 
b. Mengumpulkan gagasan dari beberapa sumber keanggotaan.

c. Melakukan musyawarah antar anggota mengenai ide produk yang akan diangkat sebagai kategori nominasi.

\section{Seleksi Ide Produk}

a. Melakukan evaluasi atas hasil rundingan musyawarah

b. Memilah produk hasil dari evaluasi

c. Mempertimbangkan hasil yang akan diperoleh, menguntungkan atau tidak

d. Memilih produk sesuai kesepakatan para keanggotaan, dan dengan kesepakatan bersama, disepakatilah produk yang akan di siapkan adalah produk face scrub herbal wajah.

\section{Desain Awal}

a. Mempertimbangkan fungsi face scrub, dapat diterima di lingkungan masyarakat atau tidak.

b. Membuat logo brand agar produk dapat dengan mudah di terima di pasar masyarakat.

\section{Prototype}

a. Percobaan bahan-bahan alami yang akan dijadikan face Scurb.

b. Simulasi pertama menggunakan garam yang dicampur teh hijau c. Simulasi kedua menggunakan kunyit yang dicampur dengan teh hijau

d. Simulai ketiga menggunakan teh hijau, garam, dan kunyit

\section{Testing}

a. Melakukan uji coba bahan alami dengan menggabungkan teh hijau, garam, dan kunyit dalam sebuah wadah

b. Melakukan uji coba pada wajah para anggota.

c. Mencatat hasil eksperimen

\section{Desain Akhir}

a. Menetapkan teh hijau, kunyit dan garam sebagai bahan dasar pembuatan Face Scrub Herbal

b. Menetapkan jenis wadah atau kemasan obat herbal

c. Menetapkan logo sticker pada wadah

\section{Implementasi}

a. Memulai pembuatan produk facescrub herbal

b. Memulai pembuatan kemasan produk face scrub herbal

c. Melakukan sosialisasi ke tetangga atau sanak saudara

d. Melakukan sosialisasi ke masyarakat 


\section{KESIMPULAN DAN SARAN}

\section{Kesimpulan}

1. Face Scrub Tekuga adalah bisnis yang dapat menjanjikan karena berbahan dasar Kunyit, Teh hijau, dan Garam yang mudah ditemukan dan memiliki banyak manfaat untuk kecantikan.

2. Produk ini memiliki kelebihan dan kekurangan, sementara peluang dan ancaman berasal dari pesaing dan masyarakat yang masing masing memiliki keinginan masing-masing.

3. Pemasaran face scrub tekuga melalui media social, door to door, dan promosi dengan harga terjangkau membuat bisnis ini laku dibeli oleh masyarakat.

\section{Saran}

1. Memperluas target yang dituju,

2. Meningkatkan Penjualan TEKUGA

3. Memiliki Izin dari BPOM

\section{DAFTAR PUSTAKA}

https://www.merdeka.com/gaya/9-

$\underline{\text { manfaat-kunyit-untuk-kecantikan.html }}$

https://doktersehat.com/manfaat-teh-

hijau-untuk-kecantikan/

https://hellosehat.com/hidup-

sehat/kecantikan/berbagai-manfaatgaram-untuk-wajah/ 